\title{
Geografía y vías de comunicación en Sudamérica. Apuntes para un estudio desde Bolivia
}

\section{Geography and communication routes in South America. Notes for a study from Bolivia}

\author{
Clara López Beltrán \\ Academia Boliviana de Historia \\ Bolivia \\ mariaclara.lopezbeltran@gmail.com
}

\section{Resumen}

La República de Bolivia construyó su Estado sobre un escenario geográfico y poblacional que necesitaba ser integrado para consolidar su afiliación nacional. Esta investigación analiza, desde la perspectiva histórica, el proceso de ensamblaje territorial, construido en torno al Camino Real de Charcas, utilizando como estudio de caso el actual territorio boliviano ubicado en el centro geográfico de Sudamérica.

Palabras clave: Bolivia; Audiencia de Charcas; territorio; vías de comunicación; geopolítica sudamericana.

\begin{abstract}
The Bolivian Republic had been created on a not integrated geographical space, located in the core or South America. This research analyzed, from an historical perspective, the building process around the Camino Real de Charcas, the main regional road in this Andean area.
\end{abstract}

Key words: Bolivia; Audiencia de Charcas; Bolivian territories; roadways; geopolitics.

Recibido: 01/04/2021 Aceptado: 06/07/2021 
Allí, pues, donde acuden a encontrarse los Andes peruanos, bolivianos, chilenos y argentinos, adquiere la cordillera sus mayores proporciones en altitud y espesor, en el núcleo mismo de esta convergencia orográfica multinacional está el Macizo Boliviano (Mendoza, 2016 [1935], p. 256

Las relaciones internacionales del continente americano han tropezado en los últimos dos siglos, --desde el surgimiento de los estados independientescon complicados obstáculos a la hora de aclarar el dominio, la proyección y la soberanía sobre la jurisdicción de territorios a gobernar. Para la América hispana la idea de integración significaba superar las divisiones regionales, estas divisiones fueron germinadas, por un lado, de las diferencias entre los espacios geográficos y por el otro, de los intereses económicos, sociales y de poder. Esta presentación quiere llamar la atención sobre algunos procesos históricos complejos, de larga duración y de enorme trascendencia como lo fue la organización del territorio americano a partir de las políticas de gobierno y ordenamiento territorial de la Corona española, y que después, en la mayoría de los casos, influirían en la construcción de los Estados independientes, manteniendo un orden estructural heredado.

Esta pesquisa analiza desde la perspectiva histórica el proceso de ensamblaje territorial, utilizando como estudio de caso el actual territorio boliviano ubicado en el centro geográfico de Sudamérica. La República de Bolivia se creó por el principio de luris possidetis juris ${ }^{1}$ sobre el espacio geográfico jurisdiccional de la Audiencia de Charcas. Este territorio está atravesado a lo largo de su toda su extensión, --tendencialmente de norte a sur--, por un camino que funcionó como una vía de comunicación medular de la región surandina, conocida en el período virreinal como Camino Real de Charcas; tal derrotero unía Lima con Buenos Aires siguiendo las faldas de las cumbres andinas. Se introduce luego en el Altiplano que encierra el lago Titicaca, hasta los cerros metalíferos de la región de Potosí y termina en los valles altos cercanos a la ciudad de La Plata, o la actual Sucre. Tal trazado,

${ }^{1}$ Uti possidetis iuris es el principio legal por el cual los Estados tienen dominio sobre los territorios que históricamente les pertenecen. Las repúblicas sudamericanas, en 1810, aceptaron definir sus límites usando aquellos que la Corona española puso entre las distintas gobernaciones y virreinatos. 
que conecta diferentes ecosistemas, se perfiló secularmente en varias atapas desde la época prehispánica (Dollfus, 2014).

El objetivo de este estudio es poner en relieve el ordenamiento territorial comprometido por la actual Bolivia, hilvanado a lo largo de su historia por corredores de circulación útiles para el contacto entre individuos y para el intercambio de objetos, provisiones y saberes; al mismo tiempo son un elemento estrechamente relacionado con el poblamiento y por tanto con la articulación social del territorio. Esta ruta, parte de una red más amplia de travesías de intercambio con ramificaciones laterales. Funcionó como engranaje de transmisión para impulsar las corrientes de integración territorial, involucrando pueblos unidos por lazos históricos y culturales. A lo largo de la historia, la ruta troncal de Charcas, después Bolivia, encontró dificultades en el proceso de integración internacional que truncaron o dificultaron el flujo rotatorio, debido a factores gubernativos y a la carencia de políticas públicas de largo aliento.

\section{La ruta diagonal Sudamericana}

La historiografía de la segunda mitad del siglo pasado ha demostrado cómo los territorios de gran parte de Sudamérica (a excepción de las zonas amazónicas) estuvieron ágilmente conectados de costa a costa. Este encadenamiento de trayectorias, permitió la construcción de políticas encaminadas a establecer un ordenamiento estructural que contribuyera en el manejo de los intercambios económicos, así como, en el relacionamiento de grupos sociales y nacionales

La red de caminos articulaba quince grandes ecorregiones a lo largo de la cordillera de los Andes. Es relevante destacar que, dentro de estas ecorregiones articuladas en el Qhapaq Ñan, se ubican importantes espacios naturales. Desde una perspectiva actual, esta importante red vial integra directamente trece áreas naturales protegidas de orden nacional distribuidas entre Ecuador Perú Bolivia Chile y Argentina (Díaz Palacios, 2016, p. 84).

Dichas rutas fueron delineadas por necesidades de dominio espacial y de gobierno de la Corona española para asentar su poder e incorporar sus territorios indianos a los de España. Ya en la segunda mitad del siglo XVI, la Corona y su gobierno idearon un armazón legal y reglamentario encaminado a consolidar el ordenamiento del suelo recién incorporado al imperio español. 
Este gran proyecto de gobierno estuvo basado en un gigantesco proceso de urbanización, acompañado por el establecimiento de "caminos reales ${ }^{2}$ o rutas privilegiadas promocionadas por la administración real o virreinal (Pérez González, 2001).

La red de caminos virreinales utilizó las calzadas empleadas por los pobladores originarios. En el virreinato del Perú se usó la red de caminos troncales de la conocida red de caminos incaicos actualmente visibilizado como Qapaq Nan ${ }^{3}$ cuyo trazado y construcción se inició en la etapa pre-inca para después consolidarse con la organización imperial del Tawantinsuyu. Fueron éstas las arterias de comunicación para la conquista terrestre española en Sudamérica, para luego, en los siglos sucesivos, funcionar como derroteros de circuitos mercantiles y de abastecimiento del periodo indiano y de la independencia. Con ello marcaron la estructura del orden territorial de las jóvenes republicas sudamericanas, por lo menos su primer siglo de vida. Esto es cierto para el caso de la actual Bolivia.

\section{Eslabón andino central: el "Camino real" de Charcas}

Las vías de comunicación promocionadas por la Corona española cumplieron un papel fundamental para el desarrollo comercial y minero. Facilitaron el acceso de recursos naturales aprovechando la configuración física del entorno, impulsando el manejo del territorio mediante la intervención del paisaje. Así, se crearon diversas estrategias de aprovechamiento de los recursos naturales, basadas en sistemas madurados a partir de dos vertientes principales, por un lado, por los conocimientos avanzados por las

\footnotetext{
2"Camino Real" es aquel que tiene interés especial para la Corona y está construido a expensas del Estado. Las tempranas leyes castellanas de las Partidas de Alfonso X el Sabio dicen, "Otrosí debe mandar labrar los puentes y las calzadas, y allanar los pasos malos porque los hombres pueden andar y llevar sus bestias y sus cosas desembargadamente de un lugar a otro, de manera que no las pierdan en el pasaje de los ríos, ni en los otros lugares por donde fueren" (Partida 2, tit. 11, ley 1 de las Siete Partidas de Alfonso $X$ el Sabio).

3"Qapaq Ñan": era la extensa red de caminos incaicos o pre-incaicos, de caminos de construcción formal, consolidado en el siglo XV por los incas, que tuvo como objetivo articular los diversos pueblos del Tawantinsuyu para una eficiente administración de los recursos.

En junio de 2014 este conjunto caminero fue declarado Patrimonio Mundial de la Humanidad por la UNESCO.
} 
sociedades prehispánicas y por el otro, por los saberes de la cultura europea rápidamente absorbidos por la población indiana (Roca, 2007, p. 576).

Dichas veredas facilitaron el desplazamiento de la población en general. La constante actividad ayudó eficazmente en los territorios organizados en virreinatos, al traslado de la mano de obra hacia las minas de plata o de mercurio (recurso necesario para la concentración del metal). También circularon todos los géneros de abasto y manufacturas de producción local junto con las más variadas mercaderias llegadas desde diversas regiones europeas (mediterráneas y nórdicas), también americanas (Nueva España), y excepcionalmente de Asia (Filipinas). Las élites locales y el imaginario popular estaban conscientes y orgullosos de las riquezas que producían y custodiaban que quedaban reflejadas en las cuantiosas sumas recaudadas por sus Cajas Reales, los recursos generados por la población indígena y la articulación comercial. En el caso de Charcas, su posición geográfica, su riqueza natural y la alta concentración demográfica en las tierras altas tuvo una densa actividad en trayectos cortos o en aquellos de largo alcance.

El Camino Real de Charcas fue impulsado por la Corona y fue una consecuencia evidente de la creación de la Real Audiencia de La Plata en Charcas hacia $1560^{4}$. Esta nueva unidad judicial obedeció a los intereses españoles sobre una poderosa región argentífera de Potosí y Oruro donde, la capacidad de control desde Lima no tuvo la potencia para a dominar el empuje económico del auge minero y la nutrida población que lo sustentaba con su trabajo. La jurisdicción de la Audiencia fue vagamente demarcada por virrey Conde de Nieva en 1561 asignándole, de manera aleatoria, un control administrativo sobre una superficie "con más de cien leguas de tierra alrededor de cada parte" a partir de la ciudad de La Plata (hoy Sucre). Fue una selección acertada ya que ese espacio geográfico -costa, montaña y tierras bajas- se adecuó con eficiencia al nuevo régimen

Los informes de los primeros españoles ya señalaban como puntos de referencia de la ruta los conocidos "tambos" o mesones de abastecimiento para viajeros y bestias de carga, situados a la vera del camino. Algunos de estos tambos, con el tiempo, se transmutaron en pueblos de indios o puntos habitacionales para la población indígena, basados en un orden urbanístico

\footnotetext{
${ }^{4}$ La Real Audiencia de La Plata en Charcas fue creada por el rey Felipe II de España por Real Cedula del 4 de septiembre de 1559 y regulada por las Reales Cedulas de 29 de agosto de 1563 y $1^{\circ}$ de octubre de 1566.
} 
municipal y la presencia de un párroco para la evangelización. Estos tambos fueron señalados en las Ordenanzas de Vaca de Castro (1543) y luego indicadas solo a modo referencial en la Crónica del Perú de Cieza de León [1553] y un elenco poco ordenado en Nueva Crónica y Buen Gobierno de Guamán Poma de Ayala (1615).

La Corona española supo, a su llegada a tierras peruanas, que era urgente controlar este territorio densamente poblado y socialmente estructurado y asentar soberanía en el sur del Collasuyu, es decir, en los tradicionales territorios del pueblo aymara aglutinados torno al Altiplano Andino, y, por otro lado, frenar las incursiones de los rebeldes chiriguanos, grupo de lengua tupiguaraní. Sin embargo, fue la Villa Imperial de Potosí la que, por su riqueza argentífera, ejerció de centro motor del sistema de gobierno fomentado por el virrey Francisco de Toledo. Al mismo tiempo, las ciudades diseñadas para la residencia de españoles se convirtieron en los puntos de referencia que permitía a los nativos y extranjeros moverse en una gran extensión incorporándola a la administración virreinal. Así, la distribución espacial de los nuevos asentamientos, suscitaron la promoción de itinerarios cuyos trazados fueron estratégicamente diseñados a los que se les concedió los privilegios de Camino Real ${ }^{5}$ (figura 1 ).

\footnotetext{
${ }^{5}$ No se pudo encontrar mejores palabras para describir el trayecto toledano que las escritas en 1596 por el corregidor de La Paz, Diego Cabeza de Vaca en su Descripción de La Paz y dice: "Solían estar en poblazones derramadas porque cada parcialidad ayllo o linaje, estar poblados en las tierras donde tenían sus sementeras y heredades, y un cacique solía tener quince o veinte o treinta pueblos debajo de su mandado y después que el Virrey don Francisco de Toledo hizo la visita general, se redujeron todas estas parcialidades y linajes a pueblos poblados en forma de república, con calles y plazas, donde tienen sus iglesias y parroquias y tienen sus alcaldes y regidores y forma de ayuntamiento, poblándoles en la partes más cómodas que parecieron, poblando primero los caminos reales; y si la parcialidad y dominio de algún cacique no bastaba para hacer pueblo entero y para tener sacerdote que los doctrinase, se han juntado dos y tres caciques, aunque el amor de los lugares donde se criaron y la poca gana que algunos tienen de estar donde sean vistos, les hacen dejar los pueblos poblados y volverse a sus estancias antiguas, pero no en la norma que antes estaban".
} 
Figura 1: Camino Real de Charcas y Ruta de La Plata

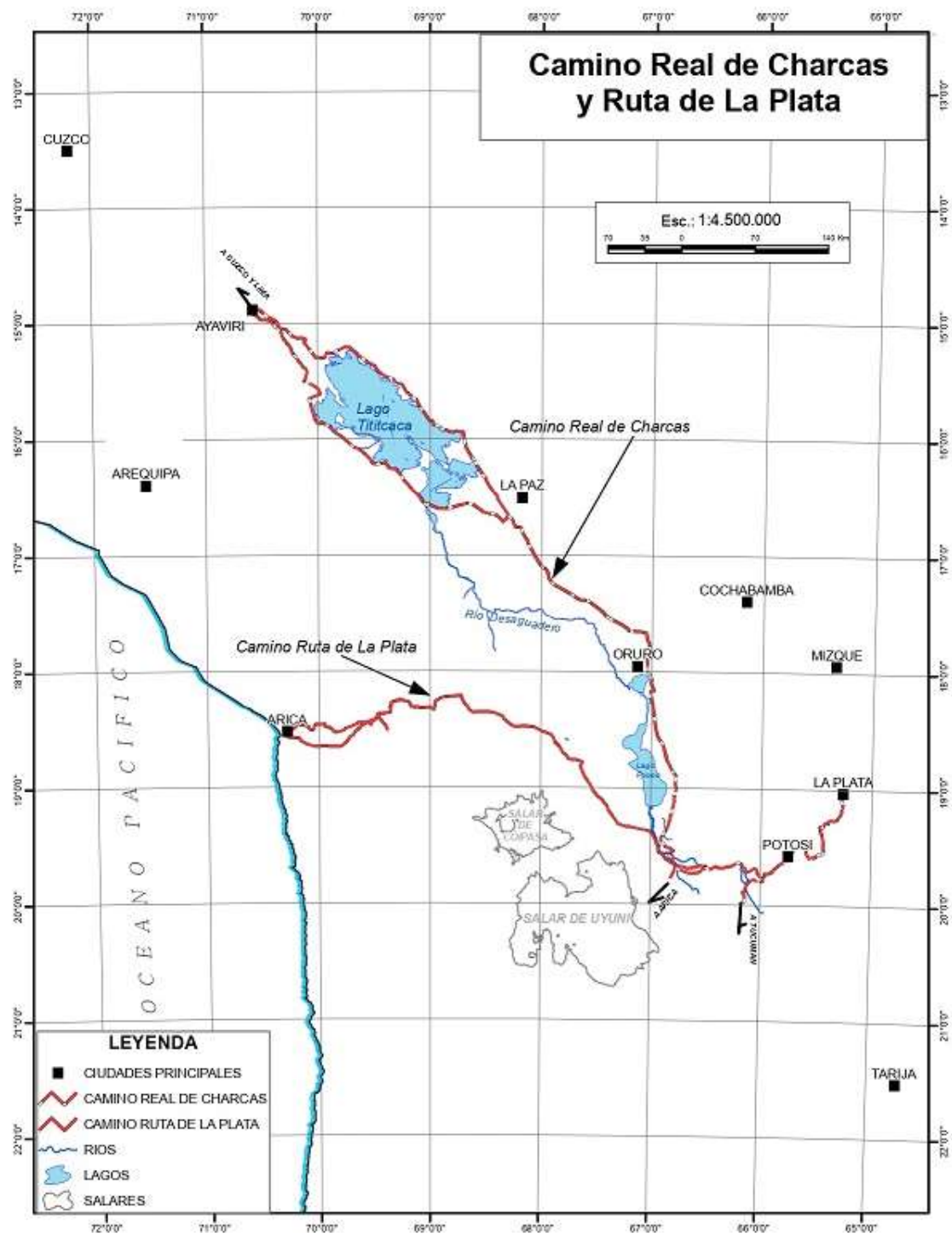


Los privilegios que trae y atrae un Camino Real son de carácter económico y social por la movilización de individuos que, impulsados por la necesidad de contacto con las comunidades de su entorno y de referencia lo transitan en particular por el intenso intercambio comercial o de transporte. Estas dos razones hicieron que el actual territorio actual de Bolivia estuviera integrado por dos caminos reales cumpliendo cada cual un papel diferente pero complementario.

El primero es el Camino Real de Charcas que tiene como punto de arranque el pueblo de Ayaviri, (inicio convencional) hasta la ciudad de La Plata (sede de la Audiencia de La Plata) pasando por la Villa Imperial de Potosí (centro neurálgico de la actividad minera argentífera). Atravesaba de norte a sur este camino real el territorio de la Audiencia de Charcas, incorporando a la nueva economía mercantil a pueblos aymaras dedicados a la agricultura y la ganadería, vocación que se ha mantenido hasta el presente, con eventuales innovaciones tecnológicas.

\section{Camino Real de Charcas}

El recorrido estudiado enfrenta al transeúnte con cambios de paisaje y temperaturas propias de los climas de montaña con variables de hasta $20^{\circ} \mathrm{c}$. del día a la noche: Considerando estas características dividiremos el recorrido en tres etapas que son: la lacustre, la altiplánica y los valles altos.

\section{Primera etapa: El lago Titicaca y su entorno}

Funcionalmente Camino Real de Charcas se iniciaba con la entrada al territorio de los collas en el poblado de Ayaviri, punto donde el trayecto se bifurcaba abrazando el lago Titicaca por ambas orillas. La calzada discurría a una altura media de $3.800 \mathrm{msnm}$. atravesando los territorios étnicos de los Colla, Omasuyos, Lupaca y Pacajes, bajo la influencia del lago Titicaca y del río Desaguadero. Un poco más al sur, cerca del hoy casi desaparecido lago Poopo, estaban las tierras de los Charca y después los Caracara o Qaraqara.

El sagrado lago Titicaca era realmente generoso con estos habitantes aymaras ofreciendoles un habitat abrigado que permitía a los moradores dedicarse a la agricultura. Los colla y omasuyos no sólo contaban con tierras más fértiles sino además con derroteros hacia la zona aurifera de Carabaya. Por caminos secundarios alternativos se desplazaban hasta la amazonia andina a través de los valles de Larecaja y allí contactaron con otros pueblos 
llegados desde las llanuras selváticas navegando a contracorriente por el rio Tuichi o el rio Tipuani -afluentes del gran río Beni- que fueron las rutas naturales de desplazamiento.

El trazado de la parte uma (mitad menor) del Camino Real seguía la orilla oriental del Titicaca tuvo estaciones de reposo en los pueblos de Taraco, Huancane, Moho, Huaycho (hoy Puerto Acosta), Escoma, el puerto lacustre de Carabuco cuya iglesia encierra notables cuadros para la evangelización con el juicio final y el infierno. Igual que los anteriores poblados, Ancoraimes, Achacachi, Huarina y Pucarani se instalaron sólidamente en torno a sus caciques a partir del modelo de reducción, por lo que todos tienen un orden urbanístico a damero y, en especial, vistosas iglesias con portales tallados en piedra.

El recorrido urcu (mitad mayor) por la orilla occidental tiene una historia aún más sólida respecto a las reducciones, porque allí se asentaron los dominicos ya en 1534 reuniendo a las colectividades en pueblos para su evangelización; sólo en 1577 se asentaron en la zona los jesuitas, con autorización del virrey Toledo. Juli fue, quizás, el asiento más conocido por su elevada actividad cultural y la presencia del lingüista Ludovico Bertonio y del pintor Bernardo Bitti, tan apreciados en la historia cultural de virreinato peruano. Acompañaban a Juli otros prósperos pueblos como Puno, Acora, Chucuito, llave, Pomata y Zepita, todos ellos con sorprendentes y excepcionales templos utilizados para reunir a la nutrida población del entorno. Estos pueblos sirvieron para promover un intenso intercambio comercial y sirvieron también de lugar de descanso para las caravanas y viajeros.

Llegar a Desaguadero significaba cruzar el río del mismo nombre atravesando un puente flotante hecho de barcazas de caña de totora trenzadas colocadas una al lado de otra, a modo de flotadores, y sobre ellas capas de barro amasadas con más paja para darle solidez y continuidad al terreno; material que sin duda necesitaba que ser reemplazado frecuentemente. Llegar a Guaqui tuvo que ser un alivio para los viajeros y trajineros al haber superado el obstáculo fluvial. A partir de este punto el recorrido del camino real penetra en el altiplano andino por extensiones llanas de externas planicies con pequeños desniveles de fácil resolución. Continuando por la vereda y a pocas leguas de Guaqui, las caravanas pasaban delante del pueblo de Tiahuanaku cuyas ruinas no impresionaron al extranjero ya que sólo sabían "Que está en el camino real del Cuzco a Potosí 
(...) y parecen edificios antiquísimos de tiempos del inga y algunos dellos están hechos en cerros a manera de fortaleza...".

\section{Segunda etapa: El altiplano andino}

Continúa la ruta por superficies onduladas para hecer etapa en Viacha con un cacicazgo poderoso que se proyectó durante varias generaciones. Tuvo una posición privilegiada por ser el lugar donde las veredas Urcu y Uma convergían. Este un cruce de caminos. "que está en el camino real de Potosi" y cuya ubicación es inestimable por estar en el lugar que "Parten términos [dividen límites] con los indios de Caxa [Laja], Calamarca y Caquiaviri". Asimismo, la importancia de Viacha y de su poderoso cacique se incrementó con la cercanía de la ciudad de La Paz, fundada en 1548 en una quebrada conocida como Chuquiago. El pueblo de Viacha, de consecuencia, capturaba todo el tránsito de personas y merdacerias desde La Paz, para incorporarlo al Camino Real de Charcas. Dice la Relación de 1580 que "Esta ciudad [La Paz] esta cuatro leguas desviada del camino real que va y viene de las partes susodichas, y se tuerce un poco el camino para entrar en ella".

Desde el poblado de Viacha el camino prosigue Desde este punto, el camino ingresa con dirección sureste hacia el Tambo Real de Paria. Este último sector del camino todavia es coocido por la población más antigua de Caracollo como el Pariñan. (el camino a Paria).

Desde el pueblo de Viacha hasta a Coroma, unos $350 \mathrm{~km}$., las caravanas atrevesaban a un largo pero socorrido tramo, muy poblado y con pocas variantes en el paisaje. Garci Gutierrez de Escobar, vecino de La Paz, en 1580 en su relacion al rey dice:

Todos estos caminos están poblados por pueblos de indios y en ellos tambos que son mesones donde se albergan los pasajeros y tienen proveimiento de grano y yerba para sus cabalgaduras y mantenimientos para sus personas y carneros de la tierra para cargar sus hatos. (Relaciones Geograficas del Perú t.ll:345).

Los pueblos de ese tramo se desarrollaron con solidez. Calamarca, Ayo Ayo y Sicasica han mantenido su orden urbanístico hasta bien entrado en siglo XX. El siguiente punto de descanso fue Caracollo. Si bien Caracollo se materializó como pueblo de indios, no perdió su tradicional vocación de tambo, actividad por la cual fue reconocido y calificado por casi todos los 
cronistas que pasaron por la zona como "tambo real de los incas". Caracollo fue el punto geográfico donde la gran vereda incaica del interior entroncaba con trochas trasversales que alcanzaban los valles de Cochabamba. El camino siguió funcionando durante la administración española y actualmente es un punto de referencia en el camino carretero de La Paz a Potosí, trazado del Qapaq Ñañ sobre la cual se construyó esa vía de comunicación de gran transito hoy.

La próxima parada era Paria, un pueblo que creció moderadamente a pesar de haber sido la primera fundación española en la región en 1535, pero no prosperó; en cambio, era un punto de reunión conocido desde tiempos preincaicos. El tambo de Paria fue descrito como un asiento inca de gran jerarquía, aunque los restos arqueológicos conocidos se hallan a pocos kilómetros del pueblo; son de modesta envergadura pero mejor estudiados que los otros sitios de la región por la arqueóloga Carola Condarco

Avanzando hacia el sur y bordeando la ribera oriental del lago Poopó, se concentraban los pueblos habitados por los grupos étnicos soras, allí los centros urbanizados más robustos fueron: Poopó, Pazña, Challapata, Santiago de Huari, Sevaruyo y Coroma, cuyas iglesias son de mediana importancia. Actualmente son municipios activos ya que de ubican sobre la actual carretera de Oruro a Potosí. La región estuvo dedicada, de preferencia, a la ganadería de camélidos --en particular llamas-- además de ocuparse de la tradicional agricultura y tener contacto con zonas mineras orureñas.

\section{Tercera atapa: la zona minera y valles altos}

La siguiente etapa deja atrás las planicies del altiplano y entran en la travesía de terrenos accidentados y de alturas sobre los $5.000 \mathrm{msnm}$. En el sitio llamado Rio Mulatos entronca con la Ruta de la Plata, otro camino real une la Villa Imperial de Potosí y el puerto de Arica. Este tramo Rio Mulatos/Villa Imperial de Potosí era altamente transitado por concentrar la circulación y compartir la trocha de dos caminos reales.

La travesía desde la Villa Imperial hasta la ciudad de La Plata recorría una distancia en de quince leguas $(83.5 \mathrm{~km}$.) y "veintitantas..." para otros, con un sendero irregular entre cabeceras de valle y quebradas. Las jornadas hasta la sede de la Audiencia de La Plata no tuvieron la actividad pujante de los tramos centrales del Camino Real de Charcas, por lo que la calzada era descuidada y desatendida aunque con bordeada de riachuelos y fértiles 
campos. La producción agrícola de esos terrenos agrícolas abastecía a los asientos mineros y, de consecuencia, pronto se convirtió en zona de haciendas de propiedad de españoles, razón por la cual no desarrolló pueblos de indios de envergadura. Los puntos de descanso y hospedaje son agradables como Chaqui, un balneario de aguas termales, Betanzos con gran producción de productos de huerta, Siporo y Yotala a $18 \mathrm{~km}$. de La Plata; todos ellos fueron lugares de descanso para las caravanas, con un clima amable respecto al altiplano. El interés viajero por llegar a la ciudad de La Plata era burocrático y de gobierno por lo que las mulas circulaban más bien cargadas de papeles y abogados que de abastecimientos y herramientas.

Colocar el punto final del Camino Real de Charcas en la ciudad de La Plata, sede de la Audiencia, responde a la importancia que la administración de la corona le dio a la ciudad, pero también al hecho que el virrey Toledo la consideró una punta de lanza de su control territorial y ser la base operativa para lanzar la guerra contra los chiriguanos.

\section{La Ruta de la Plata}

El segundo camino real en la Audiencia de Charcas fue La Ruta de la Plata (López Beltrán, 2016), vía que conectaba la Villa Imperial de Potosí con el puerto de Arica en la costa pacífica. Era un acceso conocido y de contacto con para el transporte marítimo. Esta vereda fue impulsada por la administración indiana con el fin de canalizar el comercio de exportación (de minerales) y de importación, y, para trasladar con precisión el Tesoro Real o el 20\% (Quinto Real) de los minerales extraídos de los varios asientos mineros. Esta vía fue delineada a finales del siglo XVI, para resolver las demandas de infraestructura que tuvo la excepcional producción de las minas de plata del distrito de Potosí; bonanza que duró varias décadas y a la que se sumó la riqueza de otros centros mineros como el de Oruro, Salinas de Garci Mendoza o los dispersos socavones de la región de Chichas. Recorría esta vereda el territorio que estuvo habitado vitalmente por grupos aymara. $\mathrm{La}$ presencia de sus tributarios y de mano de obra minera los familiarizó con la actividad extractiva minera y su entorno mercantil. Si bien esta ruta atravesaba un territorio árido, la presencia de vertientes, ojos de agua y bofedales sostenían la base vital de mulas llamas y trajineros. La parte más crítica era la bajada al litoral que transcurría por terrenos desérticos, auxiliado de tanto en tanto por algunas corrientes subterráneas y superficiales de agua dulce. 
Por lo tanto, el Camino Real de Charcas como la Ruta de la Plata fueron el conducto y correa de transmisión de la actividad mercantil, agrícola y manufacturera. Estos dos caminos fueron parte de una red caminera mayor que, a partir de la Villa Imperial de Potosí conectaba con el Pacífico en Lima vía Arica, y con el Atlántico por Buenos Aires. Todo el conjunto hilvanado por itinerarios de largo recorrido que iban integrando comercialmente las regiones en el llamado por la historiografía el Espacio Peruano (Ver figura 2: Vías de comunicación terrestre de Charcas).

El Camino Real de Charcas encadenaba por sus extremos con calzadas que se extendían hacia las costas del Pacífico y del Atlántico, estableciendo como centro estratégico de circulación la Villa Imperial de Potosí. Por mandatos administrativos, estas trayectorias fueron adquiriendo nominativos lugareños, por ejemplo, desde el norte del lago Titicaca hasta Lima fue conocido como el Camino Real del Cuzco y desde la región jujeña hasta Buenos Aires, en el siglo XVIII se llamó el Camino Real del Alto Perú ambos enlazan con el Camino Real de Charcas. Sin embargo, este corredor de contacto interoceánico es una vía sin solución de continuidad, aunque su uso y notoriedad va variando en el tiempo.

En los siglos XVI y XVII, Lima fue el centro administrativo, comercial y social del virreinato peruano y de relevante su vínculo con la ciudad del Cuzco. Esta última fue convertida por la administración indiana en un activo centro comercial de distribución, conservando al mismo tiempo su profundo significado simbólico en calidad de antigua capital del imperio del Tahuantinsuyu.

Con la creación del Virreinato del Rio de La Plata en 1776, el Camino Real del Alto Perú creció en importancia y con ello el volumen de la actividad caminera, movimiento que se desplazaba desde el centro del continente hacia la zona costera del Atlántico 
Figura 2: Vías de comunicación terrestre de Charcas

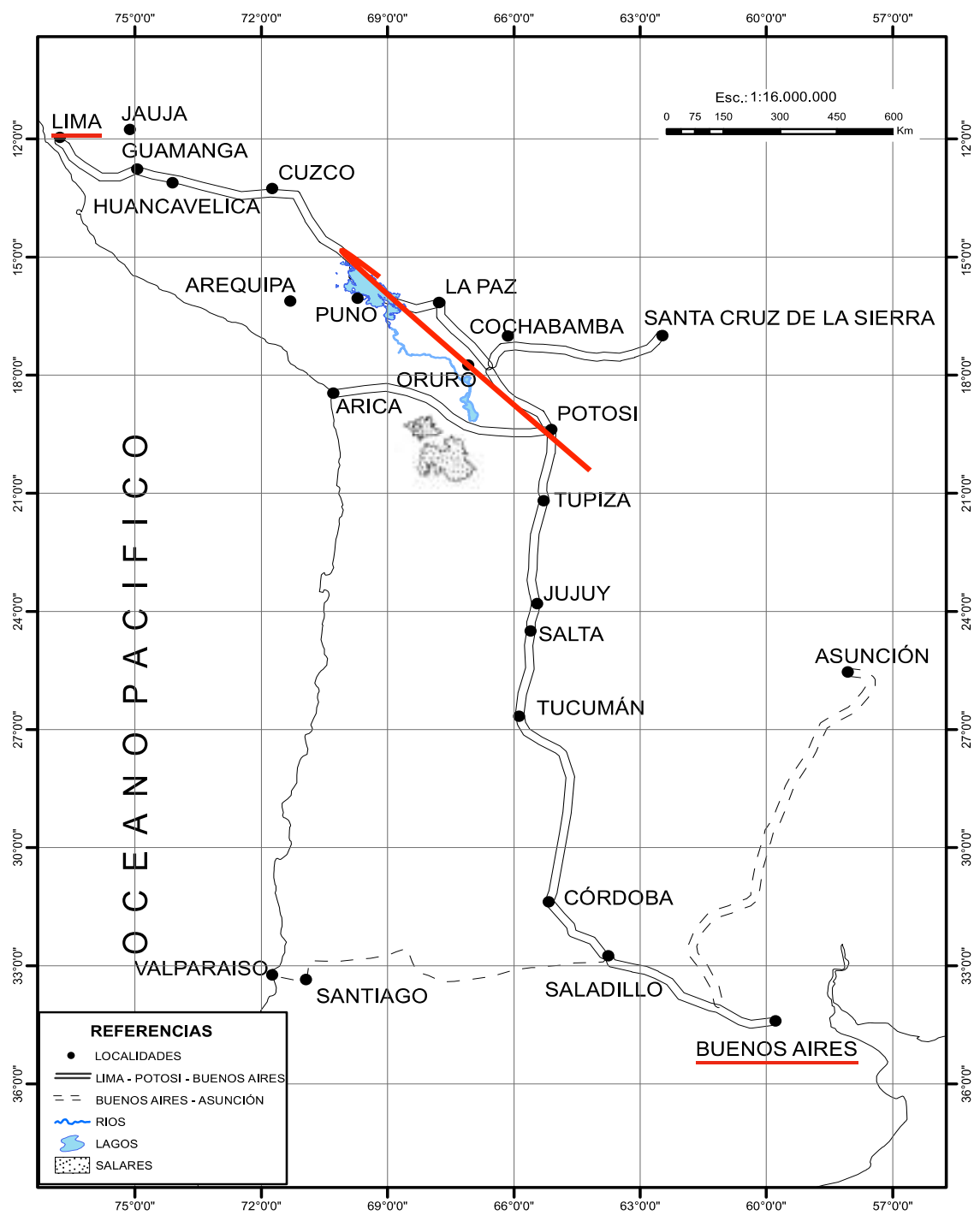


Este sistema de caminos establecidos durante la administración española encauzaba la actividad de amplios espacios entroncando con caminos segundarios integrando regiones muy diversas en su geografía, población y recursos mineros, recursos naturales, actividades productivas y de medio ambiente.

\section{Apuntes para el camino...}

Este estudio apunta a explicar el tema caminero en un estudio de caso, es decir, un trayecto vial que por siglos recogió y distribuyo población y mercaderías a partir de una región minera de Potosí y su prolongación en distancia y en el tiempo: el Camino Real de Charcas (hoy Bolivia). El tema está todavía en construcción, por lo que futuras aportaciones a la investigación permitirán conocer la influencia del entorno productivo y poblacional de los territorios nacionales, así como, conocer los obstáculos e improvisaciones que históricamente se ha enfrentado la construcción del Estado, sus políticas públicas y los cambios estructurales en la era de la globalización.

¿En qué momento el Camino Real de Charcas perdió fuelle, energía, potencia y cambio de vocación de animador regional de la actividad económica y social? En el siglo XX, por ejemplo, quedó ese tramo eliminado o desviado del trazado de la Carretera Panamericana, símbolo de la integración continental. Es tarea pendiente hilvanar en clave histórica la investigación sobre caminos y vías de comunicación con una mirada continental, así como el completarla con análisis de detalle siguiendo el trazado y su significado

Este análisis, apenas esbozado, es una apreciación panorámica de un tema a estudiarse, analizar y profundizar en la temática de integración territorial de varios países del cono sur suramericano. Es necesario conocer y comprender la influencia que las vías de comunicación, especialmente terrestres, que han influido en el prosperidad y florecimiento de las sociedades comprometidas. Un enfoque integral de las relaciones entre países debe considerar, junto a la dimensión política, un componente histórico que ilustre las imprescindibles dimensiones del escenario geográfico y poblacional donde se mueven. 


\section{Bibliografía}

Díaz Palacios, J. et. al. (2016). Historia ambiental del Perú. Siglos XVIII y XIX. Ministerio del Ambiente, MINAM.

Dollfus, O. (2014) Territorios andinos. Reto y memoria. IFEA/IEP

López Beltrán, C. (2016). La Ruta de la plata: de Potosí al Pacífico. Caminos, comercio y caravanas en los siglos XVI al XIX. Plural.

Mendoza, J. (2016) [1935]. El Macizo boliviano y el factor geográfico en la nacionalidad boliviana. Biblioteca del Bicentenario.

Pérez González, M. L. (2001). Los caminos reales de América en la legislación y en la historia. Anuario de Estudios Americanos, 58 (1), 33-60.

Roca, José Luis (2007) Ni con Lima ni con Buenos Aires. La formación de un Estado nacional en Charcas Plural/IFEA.

Torrejón Chaves, J. (1992). La ordenación del territorio como factor de desarrollo: América española en la edad moderna. Cuadernos de Geografía (3), 75-90.

Vaca de Castro, C. (2018) Ordenanzas de tambos (Cusco,1543), Perú. Ministerio de Cultura. 